This document is confidential and is proprietary to the American Chemical Society and its authors. Do not copy or disclose without written permission. If you have received this item in error, notify the sender and delete all copies.

\title{
Strong electron-donating ligands accelerate the protodeauration step in gold(I)-catalyzed reactions: a quantitative understanding of the ligand effect
}

\begin{tabular}{|r|l|}
\hline Journal: & Organometallics \\
\hline Manuscript ID & om-2016-00346w \\
\hline Manuscript Type: & Article \\
\hline Date Submitted by the Author: & $28-$ Apr-2016 \\
\hline Complete List of Authors: & $\begin{array}{l}\text { Gaggioli, Carlo; Università degli Studi di Perugia, Dipartimento di Chimica, } \\
\text { Biologia e Biotecnologie } \\
\text { Ciancaleoni, Gianluca; Universidade Federal de Santa Catarina, } \\
\text { Departamento de Química } \\
\text { Zuccaccia, Daniele; University of Udine, DCFA } \\
\text { Bistoni, Giovanni; Universita di Perugia, Dipartimento di Chimica } \\
\text { Belpassi, Leonardo; Istituto di Scienze e Tecnologie Molecolari del CNR, } \\
\text { Tarantelli, Francesco; Università degli Studi di Perugia, Dipartimento di } \\
\text { Chimica, Biologia e Biotecnologie } \\
\text { Belanzoni, Paola; University of Perugia, Chemistry, Biology and } \\
\text { Biotechnologies }\end{array}$ \\
\hline
\end{tabular}




\title{
Strong electron-donating ligands accelerate the protodeauration step
} in gold(I)-catalyzed reactions: a quantitative understanding of the ligand effect

\author{
Carlo Alberto Gaggioli, ${ }^{a}$ Gianluca Ciancaleoni, ${ }^{\mathrm{b}}$ Daniele Zuccaccia, ${ }^{\mathrm{c}, \mathrm{d}}$ Giovanni Bistoni, ${ }^{\mathrm{d}, \mathrm{e}}$ Leonardo \\ Belpassi, ${ }^{\mathrm{d}}$ Francesco Tarantelli, ${ }^{\mathrm{a}, \mathrm{d}}$ Paola Belanzoni* ${ }^{\mathrm{a}, \mathrm{d}}$
}

a) Dipartimento di Chimica, Biologia e Biotecnologie, Universita' degli Studi di Perugia, Via Elce di sotto 8, I-06123, Perugia, Italy

b) Departamento de Química, Universidade Federal de Santa Catarina, 88040-900 Florianópolis, Brazil

c) Dipartimento DI4A, Università di Udine, Via del Cotonificio, 108 - I-33100, Udine, Italy

d) Istituto di Scienze e Tecnologie Molecolari del CNR (CNR-ISTM), clo Dipartimento di Chimica, Biologia e Biotecnologie, Universita' degli Studi di Perugia, via Elce di Sotto 8, I-06123, Perugia, Italy

e) Max Planck Institute for Chemical Energy Conversion, Stiftstr. 34 - 36, 45470 Mülheim an der Ruhr, Germany

\begin{abstract}
We theoretically explore the ligand electronic effect in the protodeauration step of a model gold(I)cyclization reaction, for which experimental data are available. The mechanism of the protodeauration is investigated through a Density Functional Theory (DFT) approach and the electron-donating power of the ligand is quantified through the Charge Displacement Function $(\mathrm{CDF})$. We find that the frequently encountered assumption in the literature that "strong electrondonating ligands accelerate the protodeauration" can be set into a quantitative framework by our combined DFT/CDF theoretical approach, which allows us also to rationalize the highest catalytic efficiency of Buchwald phosphine-type ligands in this process. We analyze the ligand effect on the gold complex-substrate (LAu-S) bond strength, namely the bond to be broken during the protodeauration, and we find that the LAu-S interaction energies linearly correlate with the activation barriers. Finally, Energy Decomposition Analysis (EDA) is used to investigate the LAu-S bond, and we show that changes in the interaction energies are mainly due to changes in the electrostatic component, whose value is in turn modulated by the ligand electron-donating power.
\end{abstract}




\section{Introduction}

The last 15 years provide a clear evidence for a huge increase in the use of gold(I) complexes in homogeneous catalysis ${ }^{1,2,3,4}$. Indeed, these complexes proved to be very efficient Lewis acid for the activation of $\mathrm{C}-\mathrm{C}$ multiple bonds ${ }^{5}$ for nucleophilic attack, opening the way to complex synthetic routes.

After the rush about "what" gold complexes are able to do, some research groups focused on "how" the catalysts work, by studying the details of the reaction mechanisms ${ }^{6}$. According to the generally accepted mechanism for gold-catalyzed functionalization of unsaturated hydrocarbon compounds (UHC), the first step consists of the coordination of the gold fragment [LAu $]^{+}$to the UHC. Upon the coordination, the substrate results to be electronically depleted and prone to undergo a nucleophilic attack. Successively, the formed vinyl gold intermediate complex reacts with an electrophile (proton) to yield the final product and to regenerate the catalyst via the protodeauration step ${ }^{7}$.

Despite this simple framework, each step is affected by many factors, such as the solvent, the nature of the counterion, the presence of bases and acids and, obviously, the properties (either steric or electronic) of the ligand ${ }^{8}$. The ligand plays a major role in tuning the electronic properties of the metallic fragment ${ }^{9,10,11,12,13}$, the anion/cation relative orientation ${ }^{12,13,14}$, the outcome and the rate of the reaction, and/or even the stereo- and regio-chemistry $1^{9,10,15,16,17,18,19}$.

Recently, a few works have tried to rationalize the ligand effect in the gold(I) catalyzed reactions and new ligands have appeared in the gold catalysis scenario ${ }^{20,21}$. An example of ligand design can be found in the works by Alcarazo et al., where various cationic ligands have been synthesized ${ }^{15}$, with the precise aim of dramatically enhancing the gold complex ability to activate $\pi$ systems. An additional notable example is reported by Zhang et al. with the introduction of a basic center in the ligand, in order to direct and promote the nucleophilic attack on the coordinated UHC. ${ }^{22}$

In the exhaustive work by Wang et $a l^{23}$, the authors experimentally categorized gold-catalyzed reactions and they found that reactions for which the rate determining step (RDS) is the nucleophile attack are favored by electron-withdrawing ligands, which, in contrast, give lower catalytic activities when the protodeauration step is the RDS.

Concerning the relationship between the nature of the ligand and the kinetics of each step in the gold catalytic cycle, it is very often assumed in the literature that electron-withdrawing ligands promote electrophilic activation of the substrate (nucleophilic attack step) and electron-donating ligands promote protodeauration step. However, since the interaction between the ligand and the metal center can be complex, we cannot take the above assumption for granted and a quantitative relationship between the electron-donating/electron-withdrawing ligand power and its catalytic activity would be desirable. 
For instance, recently we theoretically analyzed the ligand effect in a gold(I)-catalyzed intramolecular alkyne hydroamination, showing that the simple "electron-withdrawing ligands are better for the nucleophilic attack step" assumption is not applicable for high acidic ligands when a $\pi$-electron conjugation between the unsaturated and the nucleophilic functionalities are present, due to the competition between alkyne activation and nucleophilic deactivation effects. ${ }^{24}$

Despite the protodeauration step has been usually considered as relatively fast, recently in some works many organogold intermediate species have been observed ${ }^{18,25,26,27,28,29}$, suggesting that in some cases the protodeauration is the RDS. For an understanding of the ligand effects in the protodeauration, Wang et al. ${ }^{23}$ specifically studied the reaction between a vinyl gold complex [LAuS] and trifluoroacetic acid (TFAH), leading to [LAuTFA] and a substituted furan-2-one (SH) as products, as depicted in Scheme 1, with different ligands, including the carbene L1, the triphenylphosphine $\mathrm{PPh}_{3}$ and its $p a r a$-substituted derivatives $\left(\mathrm{P}(p-\mathrm{Me}-\mathrm{Ph})_{3}, \mathrm{P}(p-\mathrm{MeO}-\mathrm{Ph})_{3}\right.$ and $\mathrm{P}(p$ $\left.\mathrm{CF}_{3}-\mathrm{Ph}\right)_{3}$ ), and the two Buchwald phosphines $\mathbf{L 2}$ and $\mathbf{L 3}$, bearing, in addition to the $o$-biphenyl group, aromatic and alkyl groups, respectively.
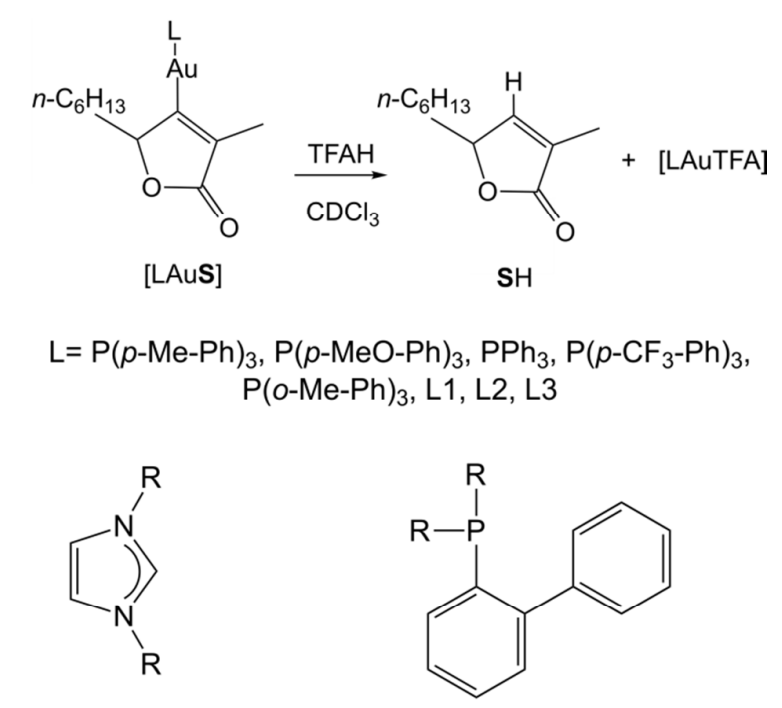

$$
\begin{array}{ll}
\text { L1: } \mathrm{R}=2,6-\mathrm{Pr}^{\mathrm{i}}-\mathrm{C}_{6} \mathrm{H}_{3} & \text { L2: } \mathrm{R}=\mathrm{Ph} \\
& \text { L3: } \mathrm{R}={ }^{\mathrm{t}} \mathrm{Bu}
\end{array}
$$

Scheme 1. Schematic representation of the experimental reaction used to analyze the ligand effect in the protodeauration step; list and structure of the studied ligands.

The kinetic study revealed that the nature of $\mathrm{L}$ has a major influence on the catalytic activity: electron-withdrawing ligands slowly decrease the rate of the reaction whereas electron-donating ligands increase the reaction rate substantially. In particular, within the $\mathrm{PPh}_{3}, \mathbf{L} 2$ and $\mathbf{L 3}$ ligand set, 
the two Buchwald phosphines gave faster protodeauration rate in the order $\mathbf{L 3}>\mathbf{L 2}>\mathrm{PPh}_{3}$. The Hammett correlation study conducted on a series of para-substituted triphenylphosphines to quantitatively determine the electronic influence of ligands showed that their activities inversely correlate with the Hammett parameter, thus demonstrating that electron-withdrawing ligands disfavor the reaction.

The ligand effects in the protodeauration step have been recently studied also from a theoretical point of view, in the comprehensive work by Ariafard et al. ${ }^{30}$, using $\mathrm{H}_{3} \mathrm{O}^{+}$as a model acid. It has been found that two important factors control the protodeauration process: the nature of the substrate, namely the alkenyl group in $\mathrm{PMe}_{3} \mathrm{Au}$-(alkenyl), which affects the reaction barrier through the strength of the $\mathrm{Au}-\mathrm{C}$ bond (the stronger the $\mathrm{Au}-\mathrm{C}$ bond, the higher the activation energy), and the nature of the phosphine ligands, confirming that more electron-donating ligands accelerate the reaction. The ligand effect has been attributed to the strengthening of the Au-P bond in the final product thus providing a thermodynamic driving force for the reaction. However, the reason why the stronger electron-donating phosphine ligands are capable of accelerating the protodeauration process has been addressed only thermodynamically and the counterintuitive result that the difference in the reactivity between the alkenyl complexes with different phosphine ligands is not explainable in terms of the LAu-substrate bond strength (the weaker the LAu-substrate bond, the higher the activation barrier) has been reported. This result is surprising since in the protodeauration step the LAu-substrate bond is typically cleaved by an electrophilic species, usually a proton, to give the desired products and regenerate the catalyst and therefore it is expected to be a crucial factor in controlling the difference in the reactivity.

Importantly, the role of the counterion has been firmly recognized in the literature ${ }^{31}$, particularly in the protodeauration step, acting as a proton shuttle ${ }^{32}$, or forming weak interactions with the substrate in order to explain the enantioselectivity ${ }^{33,34}$, or modulating the reactivity of cationic intermediates $^{35}$. The inclusion of the counterion in the protodeauration process ${ }^{36}$ is therefore pivotal for a quantitative theoretical study.

In the present paper, which represents a natural extension of our previous work on the ligand effect in the nucleophilic attack step $^{24}$, we theoretically address the issue why the "strong electrondonating ligands accelerate the protodeauration step in gold(I)-catalyzed reactions" is an applicable assumption, as it has been confirmed both experimentally ${ }^{23}$ and theoretically ${ }^{30}$ for the above model reaction, on a quantitative ground.

To this aim, we first analyze the mechanism of the protodeauration for a model ligand, in order to locate all the intermediates and transition states along the reaction path(s). We then validate the computed activation barriers through a direct comparison with the available experimental kinetic 
data for $\mathrm{PPh}_{3}$ and the corresponding p-substituted $\mathrm{PPh}_{3}$ ligands. We subsequently correlate the activation barriers for the model reaction with the electron-donating properties of $\mathrm{L}$, the latter measured by the Charge Displacement Function (see Computational Details). In order to give an interpretative framework, we finally study how the ligand is able to modify the LAu-substrate bond properties, calculated through the Energy Decomposition Analysis (EDA). The ligand effect is emphasized and generalized by introducing additional ligands, which are specifically chosen for broadening the range of their electronic properties, and which are important to extrapolate the ligand influence on the experimental observables.

\section{Computational Details}

All geometry optimizations have been performed at the DFT level of theory with the Gaussian09 package $^{37}$ using the Def2-TZVP basis set and the GGA BP86 XC functional ${ }^{38}$. To account for relativistic effects, ECP for gold has been used. All final energies have been computed with the ORCA package ${ }^{39}$ by single point double-hybrid B2PLYP ${ }^{40}$ functional calculations on the optimized BP86 gas phase structures in conjunction with the above computational details, and including the solvent effect (chloroform) by $\mathrm{COSMO}^{41}$ model. This combined BP86 geometry optimization and B2PLYP energy calculation approach has been shown to give a high accuracy to describe gold species along reaction paths in benchmark studies (we refer to it as B2PLYP//BP86) ${ }^{42}$. Unless otherwise specified, the B2PLYP functional and the COSMO are used for energy calculations. Frequency calculations at the same BP86 level of theory have been also performed to characterize all stationary points. Geometry optimization test calculations performed using BP86 and including solvent effect by $\mathrm{PCM}^{43}$ model show that optimized gas phase structures are reliable for both electronic analysis and reaction mechanism description (see Fig. S1 in the Supporting Information). Due to the fact that the investigated reactions involve two molecules ([LAuS] and the acid HTFA), the activation barriers have been computed referring to the most stable adduct involving the two molecules, in order to minimize entropy problems. Indeed, as reported in the Supporting Information of our recent communication ${ }^{44}$, where the energy profile for a similar reaction involving four molecules, $\left([\mathrm{NHC}-\mathrm{Au}]^{+}, 2\right.$-butyne, methanol, and the anion $\left.\mathrm{X}^{-}\right)$was calculated, the entropic contribution was found to be small. For this reason, computational mechanistic analysis is presented in terms of electronic energies in this work. The electron densities used for the bond characterization (Charge Displacement Function, Hirshfeld charges, and Energy Decomposition Analysis) have been computed with the ADF package (version 2012.01) ${ }^{45}$ at DFT level using TZ2P Slater-type basis sets, BP86 functional, frozen core approximation (1s for N, C, O and F, 2p for P, 
4f for $\mathrm{Au}$ ) and ZORA Hamiltonian ${ }^{46}$ to account for relativistic effects. The same level of theory using ADF has been used for working out the Energy Decomposition Analysis.

\section{Charge Displacement Function.}

An efficient way to quantify thoroughly the rearrangement of the electron density taking place upon bond formation between two fragments, is to use the Charge Displacement Function (CDF) approach, ${ }^{47}$ which allows also to estimate the exact amount of electron charge that, upon the formation of a bond, is displaced from a fragment to another one (charge transfer, CT). The CDF analysis is today a well established and successful tool for chemical bond analysis in a wide variety of context; it has been successfully used, for example, to study the chemical bond between gold(I) and the noble gases ${ }^{47}$ and bonds in organometallic chemistry. ${ }^{10,11}$ Mathematically, the CD function is defined as:

$\Delta q(\mathrm{z})=\int_{-\infty}^{\infty} d x \int_{-\infty}^{\infty} d y \int_{-\infty}^{z} \Delta \rho\left(x, y, z^{\prime}\right) d z^{\prime}$

Here $z^{\prime}$ is the axis of interest, typically one joining the interacting species (for instance, in our work, the axes that passes through the atom of the ligand bound to gold and gold $)$ and $\Delta \rho\left(\mathrm{x}, \mathrm{y}, \mathrm{z}^{\prime}\right)$ is defined as the electron density difference between the molecule electron density and that of isolated noninteracting fragments placed at the same position as in the molecule. Thus $\Delta \mathrm{q}(\mathrm{z})$ measures, at each point of the $z$ ' axis, the number of electrons that, upon formation of the bond between the fragments, moves across a plane perpendicular to the internuclear axis through the $\mathrm{z}$ point. A positive (negative) value of $\Delta \mathrm{q}(\mathrm{z})$ indicates electrons moving towards the decreasing (increasing) $\mathrm{z}$, that is from right to left (left to right). Furthermore, by looking at the slope, one can immediately deduce regions of charge accumulation (positive slope) or charge depletion (negative slope). To have a numerical estimate of the $\mathrm{CT}$, one can refer to the value of the $\mathrm{CD}$ curve at some specific point between the fragments, namely define a plane separating them. This is of course arbitrary, but as a reasonable model, which has been already used, is to take CT at the so-called isodensity boundary, i.e. the point along z' where the electron densities of the non interacting fragments become equal. All the $\mathrm{CT}$ used in this work refer to the $\mathrm{CT}$ taken at the isodensity boundary.

\section{Energy Decomposition Analysis.}

To gain insights into LAu-S bond, we carried out the Energy Decomposition Analysis (EDA) ${ }^{48}$ as implemented in the ADF package, since this method allows to decompose the LAu-S bond energy 
into contributions associated with the orbital, Pauli and electrostatic interactions. The interaction energy between two fragments is divided into three terms, as shown in eq. 2):

$$
\Delta \mathrm{E}_{\text {int }}=\Delta \mathrm{E}_{\text {elst }}+\Delta \mathrm{E}_{\text {Pauli }}+\Delta \mathrm{E}_{\mathrm{oi}}=\Delta \mathrm{E}^{0}+\Delta \mathrm{E}_{\mathrm{oi}}
$$

The $\Delta \mathrm{E}_{\text {elst }}$ is the classical electrostatic interaction between the unperturbed charge distributions of the fragments $\left(\rho_{\mathrm{A}}\right.$ and $\left.\rho_{\mathrm{B}}\right)$ at their final positions in the adduct; the Pauli repulsion $\left(\Delta \mathrm{E}_{\text {Pauli }}\right)$ arises as the energy change associated with going from $\rho_{A}+\rho_{B}$ to the antisymmetrized and renormalized wavefunction, thus properly obeying the Pauli principle and it comprises the destabilizing interactions between the occupied orbitals and it is responsible for any steric repulsion; the last term, $\Delta \mathrm{E}_{\mathrm{o} i}$, is the contribution arising from allowing the wavefunction to relax to the fully converged one, accounting for electron pair bonding, charge transfer and polarization. The sum of the electrostatic interaction $\Delta \mathrm{E}_{\text {elst }}$ and the Pauli repulsion $\Delta \mathrm{E}_{\text {Pauli }}$ terms, $\Delta \mathrm{E}^{0}$, is usually called the steric interaction energy which can be considered as a measure of the "ionic" contribution to the bond.

\section{Results and discussion}

In our theoretical investigation, the experimental reaction depicted in Scheme 1 has been modeled by replacing the $n-\mathrm{C}_{6} \mathrm{H}_{13}$ moiety in the substrate by a $\mathrm{CH}_{3}$ group and we have explicitly included a TFAH molecule. We have selected a series of thirteen ligands on the basis of their different electronic properties ${ }^{49}$, with the deliberate purpose of varying at most their electron-donating ability (Scheme 2).

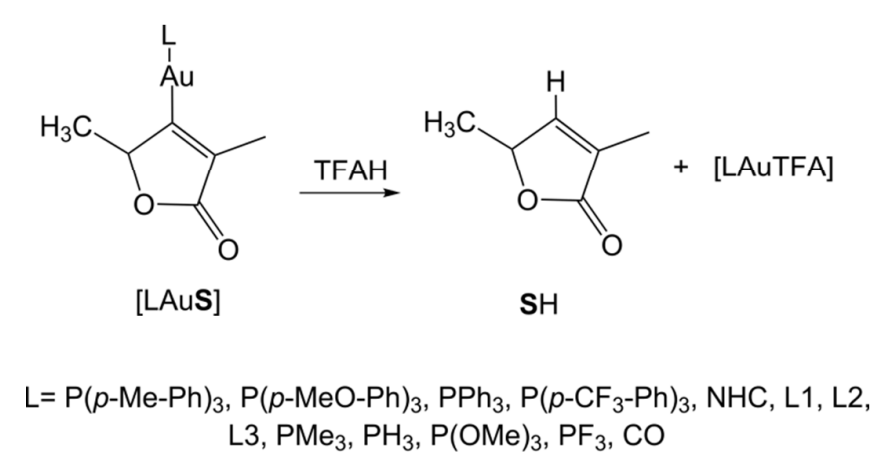

Scheme 2: Schematic representation of the computational reaction; list of the ligands studied in this work. NHC represents $\mathbf{L 1}$ with $\mathrm{R}=2,6-\mathrm{Pr}^{\mathrm{i}}-\mathrm{C}_{6} \mathrm{H}_{3}$ substituted by $\mathrm{R}=\mathrm{Me} \quad(\mathrm{NHC}=1,3-$ dimethylimidazol-2-ylidene) 


\section{Reaction path.}

We start our study by analyzing the mechanism of the protodeauration reaction in Scheme 2 choosing $\mathrm{NHC}(\mathrm{NHC}=1,3$-dimethylimidazol-2-ylidene) as reference ligand. In Figure 1 the reaction energy profile and the involved structures are shown.

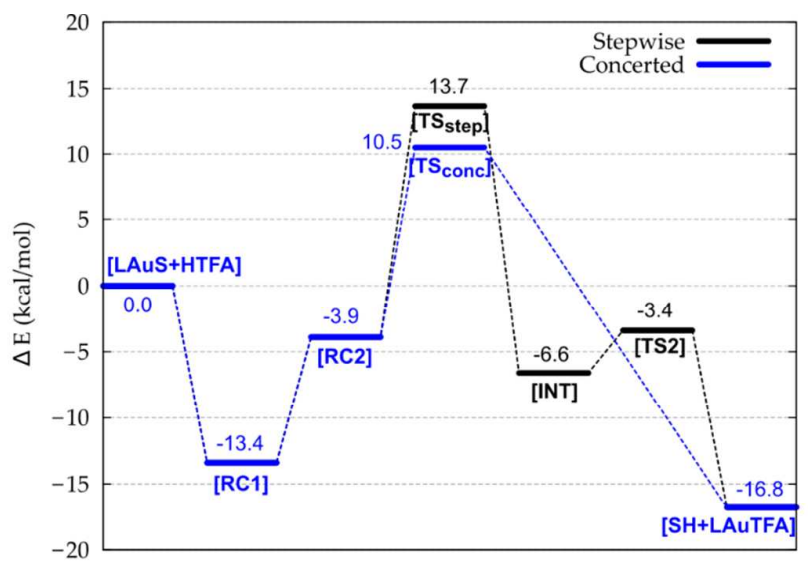

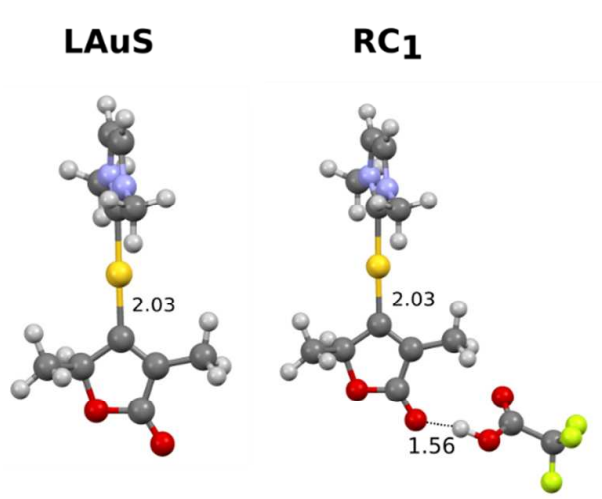

INT

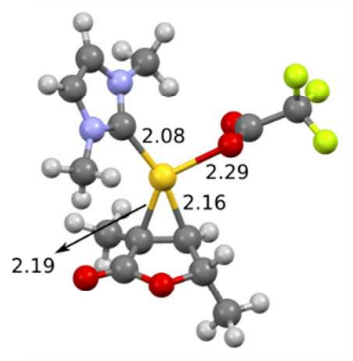

$\mathrm{RC}_{2}$
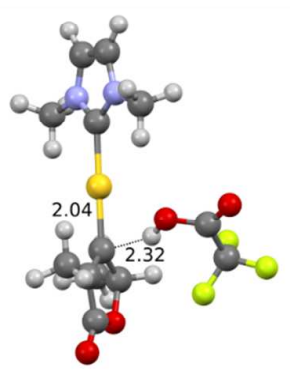

TS2

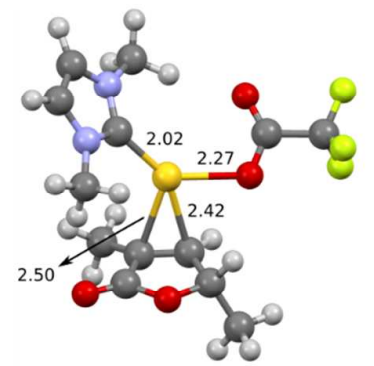

TSconc

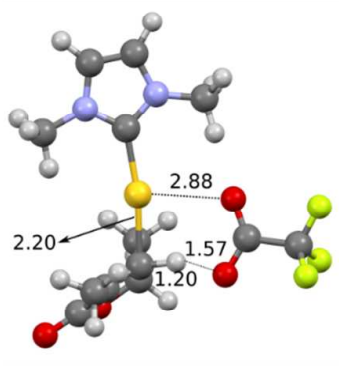

SH

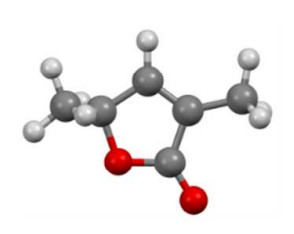

TSstep

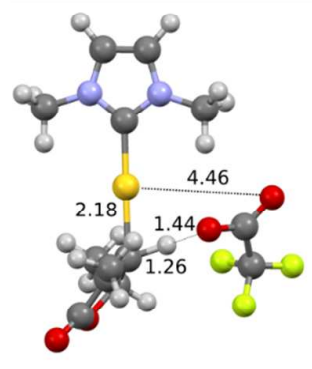

LAUTFA

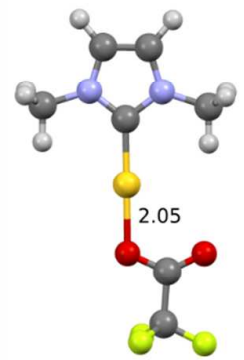

Figure 1. Top) Reaction energy profiles for the model reaction in Scheme 2 describing the protodeauration step. Energies (in $\mathrm{kcal} \mathrm{mol}^{-1}$ ) are given with respect to the isolated [LAuS] and HTFA reactants taken as zero. Bottom) Corresponding structures of the species involved in the reaction paths (all distances in $\AA$ ). 
The isolated reactants, LAuS and HTFA, are taken as zero reference energy. By approaching HTFA to LAuS, two reactants complexes are possible, depending on the position of the attacking HTFA with respect to LAuS. In the Reactants Complex 1 ( $\mathrm{RC}_{1}$ in Fig. 1), with an energy of $-13.4 \mathrm{kcal} \mathrm{mol}^{-}$ 1 , the acid is hydrogen-bonded to the substrate $\mathrm{O}_{1}$, at a distance $\mathrm{O}_{1}-\mathrm{H}$ of $1.556 \AA$. In the Reactants Complex $2\left(\mathrm{RC}_{2}\right.$ in Figure 1), with an energy of $-3.9 \mathrm{kcal} \mathrm{mol}^{-1}$, the acid forms an hydrogen bond with the carbon atom coordinated to gold $\left(\mathrm{C}_{1}\right)$, with a $\mathrm{H}-\mathrm{C}_{1}$ distance of $2.323 \AA$. From $\mathrm{RC}_{2}$ two transition states can be calculated, mainly differing in the position of the incipient $\mathrm{TFA}^{-}$anion, which lead to two different reaction paths, namely the stepwise and the concerted paths in Fig. 1. In the Transition State for the stepwise path $\left(\mathrm{TS}_{\text {step }}\right)$, which is $13.7 \mathrm{kcal} / \mathrm{mol}$ above the isolated reactants, the proton is transferring from the oxygen of the acid to the $\mathrm{C}_{1}\left(\mathrm{O}_{1 \mathrm{TFA}}-\mathrm{H}=1.440 \AA, \mathrm{C}_{1}-\mathrm{H}\right.$ $=1.259 \AA)$, thus starting to break the $\sigma$ bond $\left(2.182 \AA\right.$ ) between $\mathrm{Au}$ and $\mathrm{C}_{1}$, with the other oxygen of the anion localized away from gold $\left(\mathrm{Au}-\mathrm{O}_{2 \mathrm{TFA}}=4.465 \AA\right)$. Starting from $\mathrm{TS}_{\text {step }}$, the reaction proceeds through an intermediate (INT), which is a tricoordinated species, with gold coordinated to the ligand, to the $\pi$ system of the substrate and to the anion $\left(\mathrm{C}_{\mathrm{NHC}}-\mathrm{Au}=2.082 \AA, \mathrm{C}_{1}-\mathrm{Au}=2.159 \AA\right.$, $\left.\mathrm{C}_{2}-\mathrm{Au}=2.193 \AA, \mathrm{O}_{\mathrm{TFA}}-\mathrm{Au}=2.292 \AA\right)$, with an energy of $-6.6 \mathrm{kcal} \mathrm{mol}^{-1}$. Then the reaction proceeds to the products through a second Transition State $\left(\mathrm{TS}_{2}\right)$ (with an energy of $-3.4 \mathrm{kcal} / \mathrm{mol}^{-1}$, $\left.\mathrm{C}(\mathrm{NHC})-\mathrm{Au}=2.021 \AA, \mathrm{C}_{1}-\mathrm{Au}=2.419 \AA, \mathrm{C}_{2}-\mathrm{Au}=2.497 \AA, \mathrm{O}_{\mathrm{TFA}}-\mathrm{Au}=2.274 \AA\right)$, which shows the removal of LAu from the product $\mathrm{SH}$ and the simultaneous formation of LAuTFA with an activation barrier of $\Delta \mathrm{E}^{\neq}=3.2 \mathrm{kcal} \mathrm{mol}^{-1}$. On the other hand, in the Transition State for the concerted path $\left(\mathrm{TS}_{\mathrm{conc}}\right)$, the proton is transferring from the oxygen of the acid to $\mathrm{C}_{1}\left(\mathrm{O}_{1 \mathrm{TFA}}-\mathrm{H}=1.570 \AA, \mathrm{C}_{1}-\mathrm{H}\right.$ $=1.203 \AA)$, but the other oxygen of TFA is now pointing towards gold $\left(\mathrm{Au}-\mathrm{O}_{2 \mathrm{TFA}}=2.875 \AA\right)$. The $\mathrm{TS}_{\text {conc }}$ is more stable than $\mathrm{TS}_{\text {step }}$ by $3.2 \mathrm{kcal} \mathrm{mol}^{-1}$. From $\mathrm{TS}_{\text {conc }}$ the reaction proceeds directly to the products (see Figure 1), with an energy of $-16.8 \mathrm{kcal} \mathrm{mol}^{-1}$.

This mechanistic analysis reveals that the concerted path appears clearly favored. The activation barrier, calculated as the energy difference between $\mathrm{TS}_{\text {conc }}$ and $\mathrm{RC}_{1}$, is shown in Table 1 (entry 7) and it amounts to $23.9 \mathrm{kcal} / \mathrm{mol}^{-1}$. Table 1 also lists the activation barriers computed using the same procedure for the protodeauration of the gold complexes for all the considered ligands in Scheme 2. Our calculations show that activation barriers range from 21.5 to $33.4 \mathrm{kcal} / \mathrm{mol}^{-1}$, indicating that the electronic properties of the ligand have a major impact on the kinetics of the protodeauration.

Table 1. Activation barriers (in $\mathrm{kcal} \mathrm{mol}^{-1}$ ) for the model reaction in Scheme 2, Charge Transfer (CT) values (in electrons) for the bond between L and [AuS], and Hirshfeld CT (in electrons) using the same fragments for all the studied ligands. 


\begin{tabular}{llccc}
\hline Entry & Ligand & $\Delta \mathrm{E}^{\neq}\left(\mathrm{kcal} \mathrm{mol}^{-1}\right)$ & $\mathrm{CT} \mathrm{L}-\mathrm{AuS}(\mathrm{e})$ & $\mathrm{CT}$ Hirshfeld (e) \\
\hline 1 & $\mathbf{L 3}$ & 21.5 & -0.152 & -0.183 \\
2 & $\mathbf{L 2}$ & 22.5 & -0.138 & -0.165 \\
3 & $\mathrm{p}-\mathrm{OMe}$ & 22.7 & -0.185 & -0.172 \\
4 & $\mathrm{p}-\mathrm{Me}$ & 23.0 & -0.179 & -0.168 \\
5 & $\mathrm{p}-\mathrm{H}$ & 23.3 & -0.171 & -0.160 \\
6 & $\mathrm{PMe}_{3}$ & 23.6 & -0.169 & -0.142 \\
7 & $\mathrm{NHC}$ & 23.9 & -0.152 & -0.145 \\
8 & $\mathrm{P}(\mathrm{OMe})_{3}$ & 23.9 & -0.127 & -0.111 \\
9 & $\mathbf{L 1}$ & 24.1 & -0.096 & -0.143 \\
10 & $\mathrm{p}-\mathrm{CF}$ & 24.4 & -0.149 & -0.139 \\
11 & $\mathrm{PH}_{3}$ & 26.8 & -0.109 & -0.092 \\
12 & $\mathrm{PF}_{3}$ & 30.3 & -0.026 & -0.029 \\
13 & $\mathrm{CO}$ & 33.4 & 0.076 & 0.051 \\
\hline
\end{tabular}

In order to validate our computational approach, we analyze the calculated activation barriers for the para-substituted triphenylphosphines series (entries 3, 4, 5 and 10 in Table 1), through a comparison with the corresponding experimentally available kinetic data for the same protodeauration reaction ${ }^{23}$. The correlation plot between the experimental values of $\ln \left(k / k_{0}\right)$, where $k$ is the kinetic constant and $k_{0}$ the value for $\mathrm{L}=\mathrm{PPh}_{3}$, and the theoretical values of the activation barrier $\left(\Delta \mathrm{E}^{\ddagger}\right)$ is shown in Figure 2.

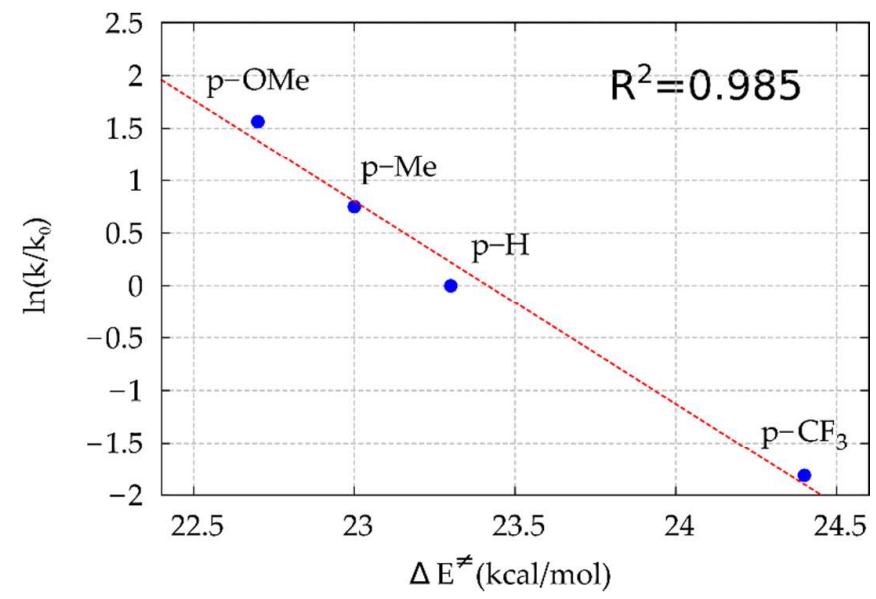

Figure 2. Correlation plot between experimental rate constants and theoretical activation barriers for the para-substituted triphenylphosphines. The labels refer to the substituent in para position of the phenyl rings of the phosphine. 
The theoretical modelling predicts lower $\Delta \mathrm{E}^{\neq}$values for experimentally faster reactions, and it nicely reproduces the experimental data $\left(\mathrm{R}^{2}=0.985\right)$ : the para-substitution of the phenyl group favors the protodeauration reaction if the substituent is electron-donating. We would like to underline that the experimental activation free energy range between the two limits (i.e. p-OMe and $\left.\mathrm{p}-\mathrm{CF}_{3}\right)$ is only $2.0 \mathrm{kcal} \mathrm{mol}^{-1}$, which is rather challenging for a comparison between theory and experiment. Nevertheless, our computational approach is strikingly able to reproduce the experimental data (both linear correlation and activation energy range between the two limits of 1.7 $\mathrm{kcal} \mathrm{mol}^{-1}$ ), and we will use it with confidence for predictive purpose throughout this work.

\section{Electron-donating ligand ability vs. protodeauration activation barriers.}

The issue we address here is how the frequently invoked assumption in the literature to explain the experimental data, namely that the more electron-donating ligands speed up the protodeauration step, could be modeled and rationalized from a theoretical point of view. To this aim, we use the Charge Displacement Function (CDF) (see Computational Details) which allows quantifying the electron donating power of the ligand. The fragments we use in our analysis are L and [AuS], with the precise aim of looking at the electron density rearrangement upon the formation of the L-AuS bond. In Figure 3 the electron density difference isosurfaces and the corresponding CD curve for the NHC reference ligand are shown.

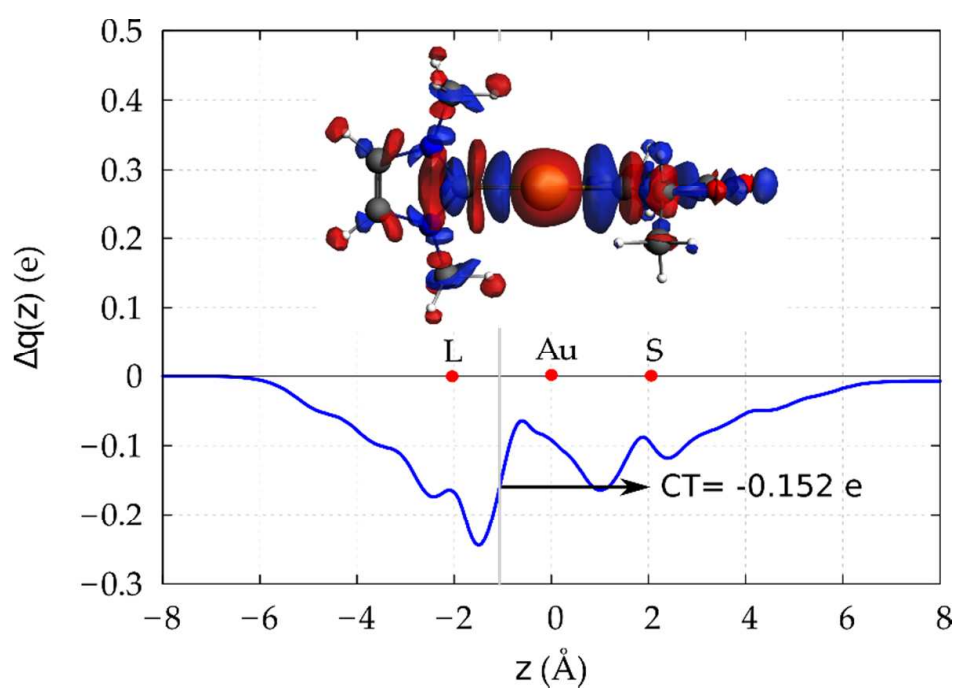

Figure 3. Top) Electron density difference isosurfaces (+/- $\left.0.001 \mathrm{e} \mathrm{au}^{-1}\right)$ using $\mathrm{L}=\mathrm{NHC}$ and $[\mathrm{AuS}]$ as fragments. Red surfaces (negative values) identify charge depletion regions, blue surfaces (positive values) identify accumulation regions. Bottom) CD curve (see Computational Details). 
Red dots indicate the $\mathrm{z}$ position of the atomic nuclei. A solid vertical line marks the boundary between the $\mathrm{L}$ and the $[\mathrm{AuS}]$ fragments.

We see that, upon the formation of the L-AuS bond, a very widespread density rearrangement takes place at both the NHC and the metallic fragment. Between the L-Au bond a sizable charge accumulation (blue) is calculated, showing the electron donation from the ligand to gold. Simultaneously, a charge depletion is observed inside the NHC ligand. Noteworthy, the NHC coordination also induces a significant charge rearrangement on the metal fragment: a charge depletion is visible on the gold atom, and an overall charge accumulation at the substrate site. With the use of the $\mathrm{CD}$ function, we can quantitatively visualize the electronic rearrangement described above and we can also extract the net Charge Transfer (CT) at the isodensity boundary, which is 0.152 electrons transferred from NHC to $[\mathrm{AuS}]$ (Figure 3, bottom).

By performing this analysis for all the studied ligands (the corresponding CD curves are shown in Fig. 4), we obtain a scale of electron-donating power of the ligands. In Table 1 CT values are reported together with the corresponding activation barriers for the entire series of ligands. All the CD curves show qualitatively the same pattern as that for NHC (Figure 4). The calculated CT values ranges from -0.185 e for $\mathrm{p}-\mathrm{OMe}$ to $\sim 0$ e for $\mathrm{PF}_{3}$ and to a positive value of 0.076 e for $\mathrm{CO}$ (Table 1). The strongest electron-donating ligands are, in the order, p-OMe, $\mathrm{p}-\mathrm{Me}, \mathrm{p}-\mathrm{H}$ and $\mathrm{PMe}_{3}$, whereas $\mathrm{CO}$ is rather an electron-withdrawing ligand. Within the CDF approach we have thus been able to provide a quantitative scale of the electron-donating/withdrawing ability of the ligand, which is also consistent with the chemical experience.

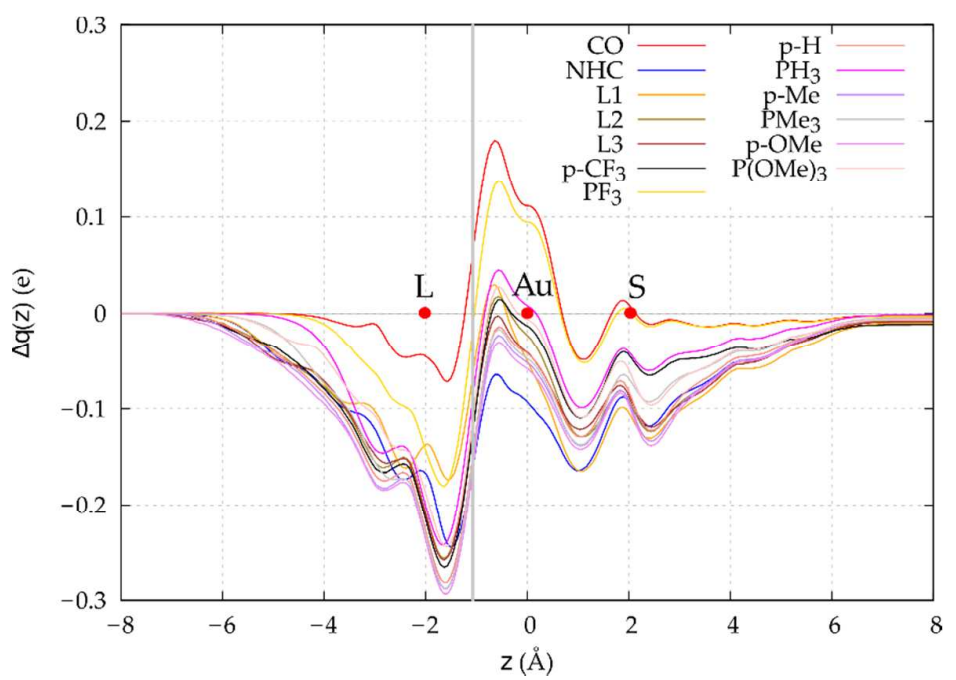


Figure 4. $\mathrm{CD}$ curves for all the studied ligands. Red dots indicate the $\mathrm{z}$ position of the atomic nuclei. A solid vertical line marks the boundary between the L and the [AuS] fragments (see Computational Details).

According to the protodeauration activation barrier values given in Table 1, L3 shows the lowest $\Delta \mathrm{E}^{\neq}\left(21.5 \mathrm{kcal} \mathrm{mol}^{-1}\right)$, although the corresponding $\mathrm{CT}$ value is not the highest, whereas CO shows the highest energy barrier $\left(33.4 \mathrm{kcal} \mathrm{mol}^{-1}\right)$ in agreement with the lowest CT value. In the plot depicted in Figure 5, the L-AuS bond CT values are correlated with the activation barriers.

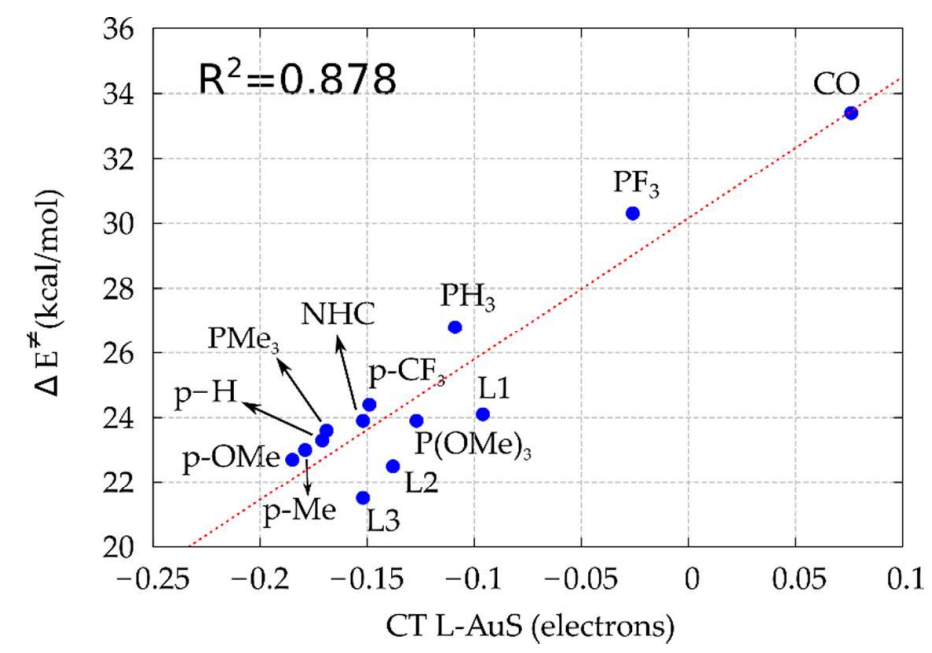

Figure 5. Correlation plot of L-AuS bond CT vs. activation barriers $\left(\mathrm{R}^{2}=0.971\right.$ on removing $\mathbf{L 1}$, $\mathbf{L 2}$ and $\mathbf{L 3}$ ) based on the values given in Table 1.

We obtain a generally good correlation between the two variables $\left(\mathrm{R}^{2}=0.878\right)$, which sets in a quantitative framework both the ligand electron-donating ability and the assumption according to which strong electron-donating ligands accelerate the protodeauration process commonly used in the literature. Interestingly, the correlation coefficient raises to $R^{2}=0.971$ if $\mathbf{L 1}, \mathbf{L 2}$ and $\mathbf{L 3}$ data are removed. Indeed, the most outlier ligands in the above correlation are L3, L2 and L1, which are also structurally distinguishable from the others.

The comparison between $\mathbf{L} 1$ and NHC in Figure 5 is strikingly since, despite the lower CT value for $\mathbf{L 1}(|\Delta \mathrm{CT}|=0.056 \mathrm{e}$, see Table 1$)$, the $\Delta \mathrm{E}^{\neq}$with $\mathrm{L}=\mathbf{L} \mathbf{1}$ or NHC are practically the same. This apparent discrepancy can be rationalized by analyzing the electron density rearrangement occurring within the ligand (namely its polarization) upon the coordination to the AuS fragment for both $\mathbf{L 1}$ and NHC (Figure 6, top). We can observe a clear polarization on the $\mathbf{L 1}$ phenyl rings which localizes in the inter-fragment region and thus coexists with the ligand to gold charge transfer. As a consequence, the CT value sums up both contributions, namely it quantifies a "pure" ligand 
donation $(\mathrm{C} \rightarrow \mathrm{Au})$ counteracted by a certain amount of the $\mathbf{L} \mathbf{1}$ polarization. At this stage, the disentanglement between the two components is not possible. In Figure 6 (bottom) the CD curves for $\mathbf{L} \mathbf{1}$ and NHC are more closely compared.
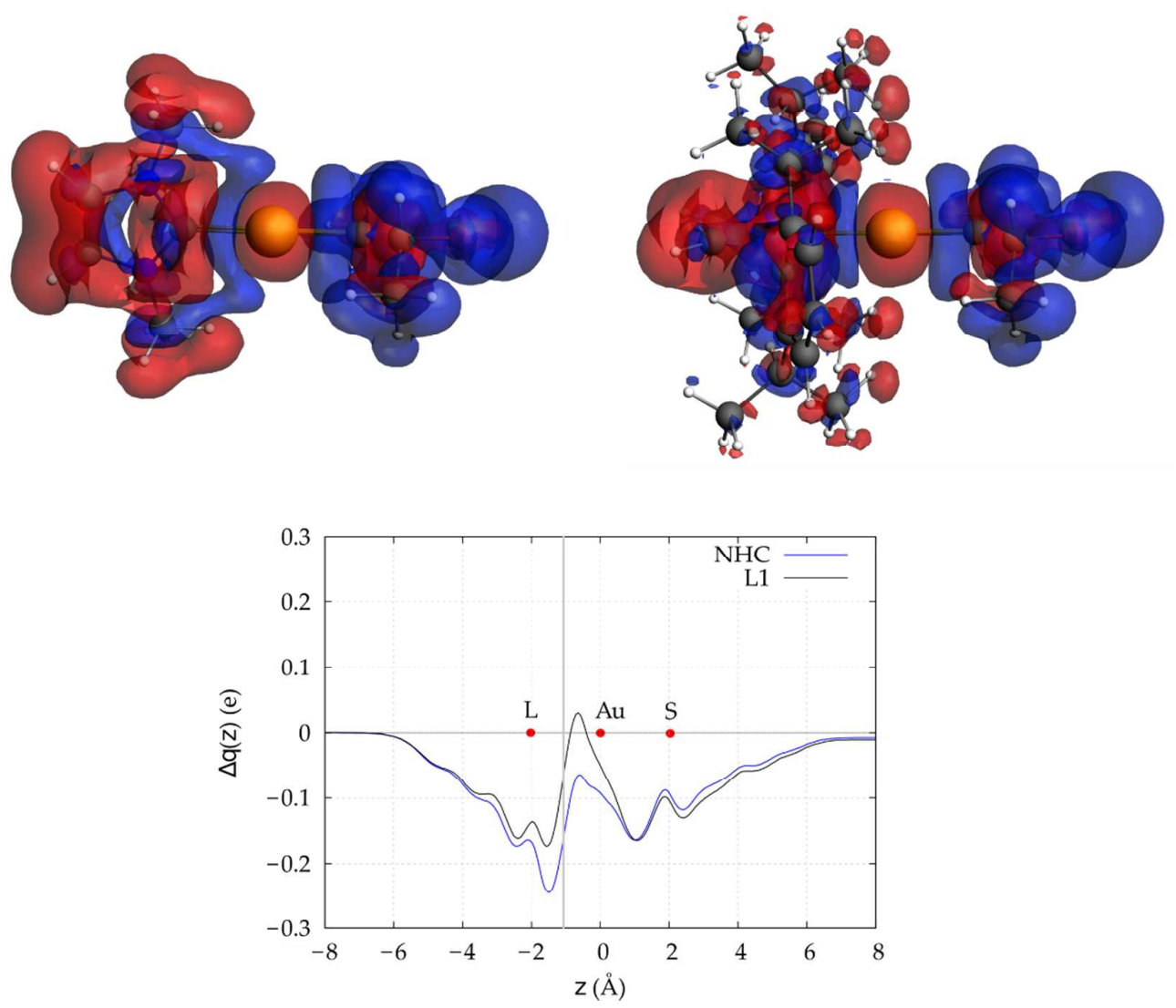

Figure 6: Top) Electron density difference isosurfaces upon formation of the L-[AuS] bond. $\mathrm{L}=\mathrm{NHC}$ (left) (isodensity value $+/-0.0003 \mathrm{e} \mathrm{au}^{-1}$ ), $\mathrm{L}=\mathbf{L} 1$ (right) (isodensity value $+/-0.0003 \mathrm{e} \mathrm{au}^{-}$ ${ }^{1}$ ). Blue (red) isosurfaces identify regions in which the electron density increases (decreases). Bottom) CD curves for $\mathbf{L 1}$ and NHC ligands.

The CD curve of $\mathbf{L 1}$ is indeed quantitatively different from that of NHC: for $\mathbf{L 1}$, the CD curve is shifted upwards in the region close to the isodensity boundary, and it shows a more pronounced electron charge depletion at the gold atom with respect to the NHC curve, while the two CD curves almost overlap in the regions around the $\mathrm{Au}-\mathrm{S}$ bond and external to $\mathrm{S}$. It is evident that the 
polarization of the phenyl rings in $\mathbf{L 1}$ is responsible for the lower CT value, whose "pure" ligand to gold electron-donation component can be estimated to be very similar to the $\mathrm{CT}$ value calculated for $\mathrm{NHC}$ (very similar $\Delta \mathrm{E}^{\ddagger}$ ).

Even more interestingly, on comparing $\mathrm{PPh}_{3}$ with the Buchwald-phosphine ligand $\mathbf{L 2}$ in Figure 5 we find that, despite the lower CT value for $\mathbf{L 2}\left(|\Delta \mathrm{CT}|=0.033 \mathrm{e}\right.$, see Table 1), the $\Delta \mathrm{E}^{\neq}$with $\mathrm{L}=\mathbf{L} \mathbf{2}$ is lower than that with $\mathrm{L}=\mathrm{PPh}_{3}$ (referred above as $\mathrm{p}-\mathrm{H}$ ) This intriguing result, which is often observed in the literature ${ }^{50}$, can be rationalized by looking at Figure 7. As already known for other metal complexes of phosphine bearing a biphenyl moiety, ${ }^{51,52}$ it can be noted that the pendant phenyl ring of $\mathbf{L} 2$ is slightly distorted, in order to allow a sidewise interaction through the ipso carbon $\left(\mathrm{C}_{i p s o}\right)$ and one of the carbon atom in ortho position $\left(\mathrm{C}_{\text {orthol }}\right)$ with gold ${ }^{51}$. This unique interaction has been previously suggested to provide stability for the resting state of Pd catalysts in various Pd-catalyzed cross-coupling processes ${ }^{53,54}$. On the other hand, although Au-arene interactions were investigated from a structural point of view for gold complexes containing Buchwald posphine $^{51}$ or other phosphine ligands ${ }^{55}$, no information are available about their influences in catalysis. In order to shed light on this topic, such a gold-pendant phenyl ring interaction can be studied by analyzing the electron density rearrangement occurring within the ligand upon the coordination to the AuS fragment for both $\mathrm{PPh}_{3}$ and $\mathbf{L 2}$ (Figure 7).
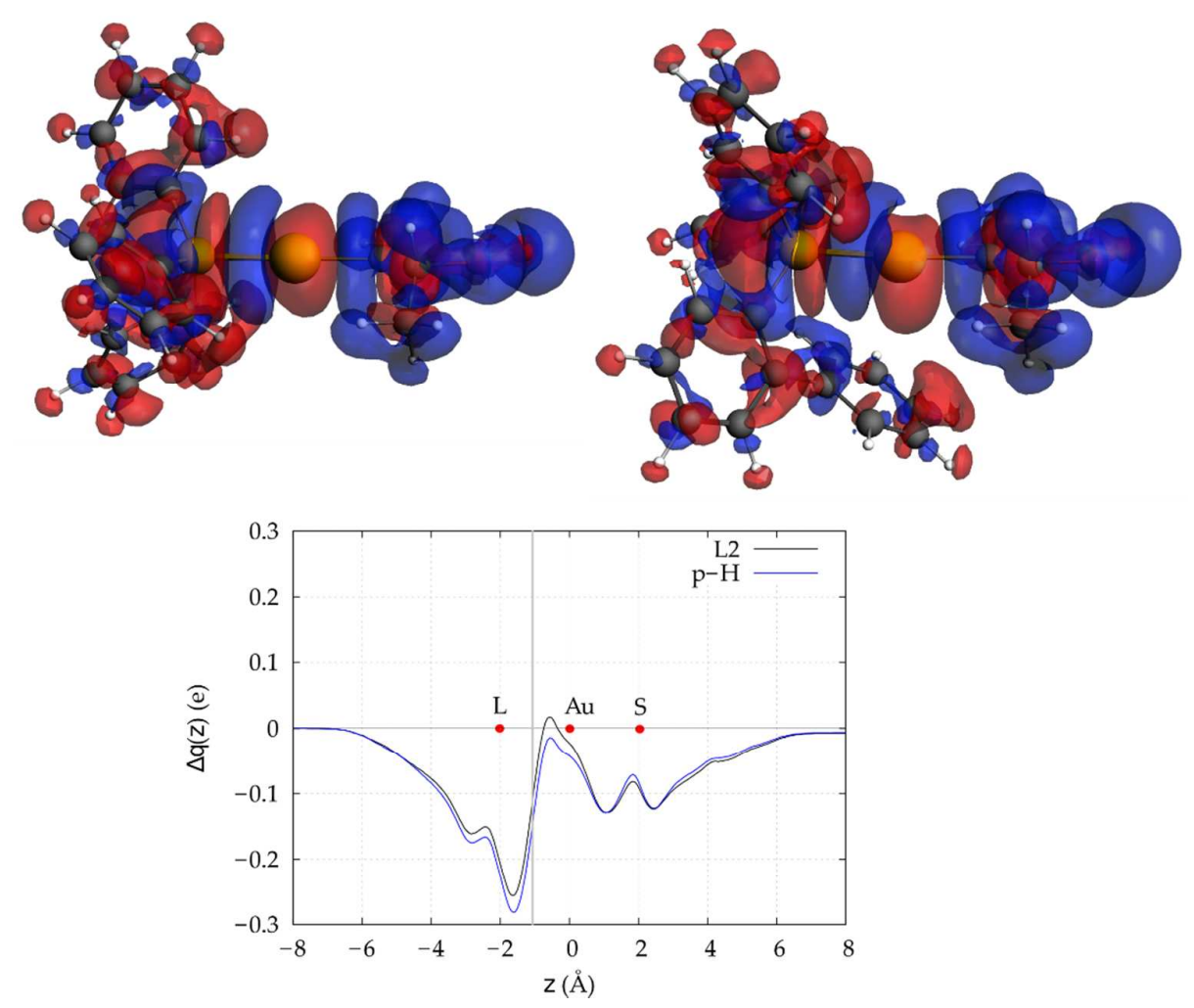
Figure 7: Top) Electron density difference isosurfaces upon formation of the L-[AuS] bond. L=p-H (left) (isodensity value $+/-0.0003 \mathrm{e} \mathrm{au}^{-1}$ ), $\mathrm{L}=\mathbf{L} 2$ (right) (isodensity value $+/-0.0003 \mathrm{e} \mathrm{au}^{-1}$ ). Blue (red) isosurfaces identify regions in which the electron density increases (decreases). Bottom) CD curves for $\mathbf{L} 2$ and $\mathrm{p}-\mathrm{H}$ ligands.

For $\mathrm{PPh}_{3}$, we can observe ligand polarization on the three phenyl rings, localizing in the interfragment region. However, in addition to that, an electron density rearrangement on the pendant phenyl ring of $\mathbf{L 2}$ (Fig. 7 top right) is clearly visible. In particular, the electron density accumulates around the carbon atoms of the pendant ring that are closest to the metal $\left(\mathrm{C}_{\text {ipso }}\right.$ and $\left.\mathrm{C}_{\text {orthol }}\right)$, causing a depletion around the meta and para positions of the phenyl. The direction of the electronic flux $\left(\mathrm{C}_{\text {ipso }} \leftarrow \mathrm{C}_{\text {para }}\right)$ is opposite to the direction of the ligand donation $(\mathrm{P} \rightarrow \mathrm{Au})$, and both of them are localized in the inter-fragment region. Moreover, due to the close position of $\mathrm{C}_{i p s o}$ with respect to gold, a negative charge accumulation in the vicinity of gold occurs in a direction perpendicular to that of the ligand donation $(\mathrm{P} \rightarrow \mathrm{Au}$ ). Thus, this particular feature distinguishes the two 3D contour plots in Figure 7 (top).

In Figure 7 (bottom), the CD curves for $\mathbf{L} 2$ and p-H are compared. Again we observe that the CD curve of $\mathbf{L} \mathbf{2}$ is quantitatively different from that of $\mathrm{p}-\mathrm{H}$ : for $\mathbf{L 2}$, the CD curve is shifted upwards in the region close to the isodensity boundary, and it shows a more pronounced electron charge depletion at the gold atom with respect to the $\mathrm{p}-\mathrm{H} \mathrm{CD}$ curve, with the two $\mathrm{CD}$ curves almost overlapping in the regions around the $\mathrm{Au}-\mathrm{S}$ bond and external to $\mathrm{S}$. These results are consistent with the aforementioned polarization at the pendant phenyl ring in L2: the two opposite fluxes of electron density (both occurring in the isodensity region) lead to a lower absolute value of the CT, which reflects the electron-donation power of the ligand $(\mathrm{P} \rightarrow \mathrm{Au})$ counteracted by the phenyl polarization component $\left(\mathrm{C}_{\text {ipso }} \leftarrow \mathrm{C}_{\text {para }}\right)$.

This powerful insight allows us to understand why $\mathbf{L} 2$ (and, in general, the Buchwald ligands) gives better catalytic performances with respect to its parent $\mathrm{PPh}_{3}$ : $\mathbf{L} 2$ does not only donate electronic density to gold through its coordination bond $(\mathrm{P} \rightarrow \mathrm{Au})$, but also the side interaction with negative charge on pendant phenyl ring $\mathrm{C}_{i p s o}$ has an effect on lowering the electrostatic contribution to the [LAu]-S bond, which, as demonstrated in the following discussion, favors the protodeauration step. A similar analysis can be applied to $\mathbf{L 3}$, which bears an identical pendant phenyl ring. In addition, L3 possesses two electron-donating tert-butyl groups instead of two phenyl rings, therefore the overall donation properties of $\mathbf{L} \mathbf{3}$ are even larger and its catalytic performances are even better than those of $\mathbf{L} 2$ (see Fig. S2 in the Supporting Information). 
An alternative way to estimate the charge transfer is the Hirshfeld charge analysis ${ }^{56}$. This allows us to give an estimation of the charge on each arbitrarily defined fragment of an adduct, computed as the integral of the adduct electron density over space, weighted at each point by the ratio between the isolated fragment density and the total density of the non-interacting fragments. Those electron density rearrangements that occur within a fragment do not contribute to the net charge of the fragment in the adduct. Using the same fragments definitions as that we used for the CD method in Figure 5, we depict in Figure 8 the correlation plot between the Hirshfeld L $\rightarrow$ [AuS] charge transfers (values given in Table 1, negative values represent a flow of electrons from $L$ to the metal fragment) and the protodeauration activation barriers. The trend again shows that the ligand electron-donating power principally affects the ease of the protodeauration process (the more electron-donating ligands lower the activation barrier), with a "stronger" positive correlation $\left(\mathrm{R}^{2}=0.972\right)$ (only the $\mathrm{P}(\mathrm{OMe})_{3}$ ligand slightly deviates from the fitting line) with respect to that between L-Au bond CT vs. activation barrier (this improvement using Hirshfeld charge transfer analysis has already been observed $)^{57}$. The comparison between the two correlation plots in Figure 5 and Figure 8 suggests that for L1, L2 and $\mathbf{L 3}$ the extrapolation of the CT value for the L-AuS bond may not be straightforward; however, the L-AuS CT analysis allows important details of the structures of these three ligands to be fully understood and rationalized.

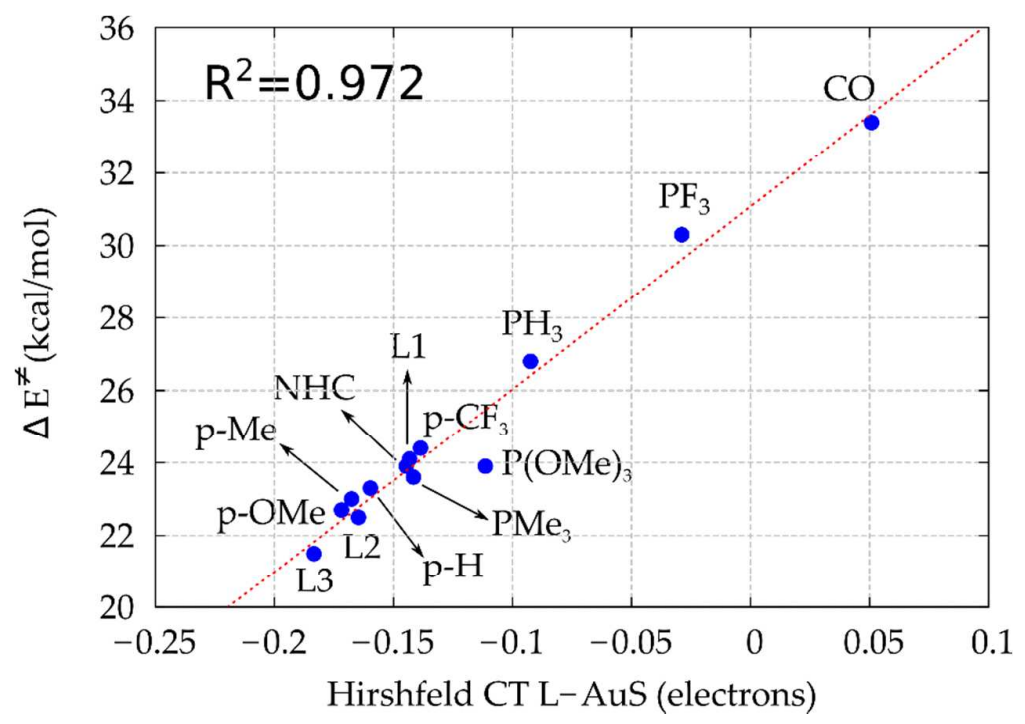

Figure 8 Correlation plot of Hirshfeld charges on the L fragment vs. activation barriers based on the values given in Table 1. 
These findings substantiate CDF analysis as a powerful tool for quantifying and describing in great detail the charge rearrangement in the [LAuS] complexes series upon the formation of the L-Au interaction.

The issue concerning how the electron-donating power of the ligand can influence the protodeauration activation barrier deserves however a further investigation. Since the reaction involves the cleavage of the Au- $\mathrm{C}_{1}$ bond, it is reasonable to question whether its strength could be a crucial factor in controlling the difference in the reactivity. In order to answer this question and simultaneously to get an insight on how the ancillary ligand L influences such a bond strength, the Energy Decomposition Analysis (EDA) of the $\mathrm{Au}-\mathrm{C}_{1}$ bond has been carried out for [LAuS], using $[\mathrm{LAu}]^{+}$and $[\mathbf{S}]^{-}$as fragments, which gives a quantitative measure of the corresponding energies. The charged fragmentation has been done since it appears to be the most chemically transparent choice for describing the ionic character of the protodeauration process, where the $\mathrm{C}_{1}$ binds to a proton meanwhile gold binds to TFA'. Moreover, the fragmentation based on $[\mathrm{LAu}]^{+}$and $[\mathbf{S}]^{-}$ enables oxidation states to be conserved and leads to closed shell fragments with no ambiguity in configurations.

In the EDA framework, ${ }^{48}$ the interaction energy $\Delta \mathrm{E}_{\text {int }}$ between $[\mathrm{LAu}]^{+}$and $[\mathrm{S}]^{-}$fragments can be decomposed into different contributions according to Eq. (2) in the Computational Details section. The calculated $\Delta \mathrm{E}_{\text {int }}$ and its energy contributions $\left(\Delta \mathrm{E}_{\text {elst }}, \Delta \mathrm{E}_{\text {Pauli }}\right.$ and $\left.\Delta \mathrm{E}_{\mathrm{oi}}\right)$ for the [LAu-S] complexes series are summarized in Table 2.

Table 2. Interaction energy ( $\Delta \mathrm{E}_{\mathrm{int}}$ ), and energy contributions $\left(\Delta \mathrm{E}_{\text {elst }}, \Delta \mathrm{E}_{\text {Pauli }}\right.$ and $\left.\Delta \mathrm{E}_{\mathrm{oi}}\right)$ for the $\mathrm{Au}-\mathrm{C}_{1}$ bond analysis using EDA. All energies are in $\mathrm{kcal} \mathrm{mol}^{-1}$.

\begin{tabular}{llrrrr}
\hline Entry & Ligand & $\Delta \mathrm{E}_{\text {int }}$ & $\Delta \mathrm{E}_{\text {elst }}$ & $\Delta \mathrm{E}_{\text {Pauli }}$ & $\Delta \mathrm{E}_{\mathrm{oi}}$ \\
\hline 1 & $\mathbf{L 3}$ & -164.9 & -311.2 & 237.4 & -91.2 \\
2 & $\mathbf{L 2}$ & -167.9 & -312.2 & 238.4 & -94.1 \\
3 & $\mathrm{p}-\mathrm{OMe}$ & -163.4 & -307.8 & 244.2 & -99.8 \\
4 & $\mathrm{p}-\mathrm{Me}$ & -167.1 & -310.4 & 240.9 & -97.7 \\
5 & $\mathrm{p}-\mathrm{H}$ & -171.5 & -314.0 & 239.7 & -97.2 \\
6 & $\mathrm{PMe}_{3}$ & -179.2 & -321.1 & 233.1 & -91.1 \\
7 & $\mathrm{NHC}_{3}$ & -177.7 & -320.3 & 229.0 & -86.4 \\
8 & $\mathrm{P}(\mathrm{OMe})_{3}$ & -185.4 & -325.0 & 234.0 & -94.3 \\
9 & $\mathbf{L 1}$ & -169.4 & -313.0 & 230.2 & -86.7 \\
10 & $\mathrm{p}-\mathrm{CF}$ & -183.0 & -322.9 & 239.5 & -99.7 \\
11 & $\mathrm{PH}_{3}$ & -200.3 & -338.4 & 232.1 & -94.0 \\
12 & $\mathrm{PF}_{3}$ & -218.7 & -351.1 & 233.1 & -100.7 \\
13 & $\mathrm{CO}$ & -228.1 & -360.2 & 232.2 & -100.1 \\
\hline
\end{tabular}


We observe from the $\Delta \mathrm{E}_{\text {int }}$ values in Table 2 that they are greatly influenced by $\mathrm{L}$, spanning an energy range of $65 \mathrm{kcal} \mathrm{mol}^{-1}$ from -163.4 to $-228.1 \mathrm{kcal} \mathrm{mol}^{-1}$ for $\mathrm{L}=\mathrm{p}-\mathrm{OMe}$ and $\mathrm{CO}$, respectively. Though the absolute values of the interaction energy are quite high for a covalent $\sigma$ bond, due to the fact that the stabilizing contribution arising from the large attractive interaction between the charged fragments, $\Delta \mathrm{E}_{\text {elst }}$, overcomes the positive (destabilizing) Pauli repulsion term, $\Delta \mathrm{E}_{\text {Pauli }}$, in gas-phase calculations, we are interested in the interaction energy trend along the ligand series. In particular, it follows from these results that the difference in the reactivity between the para-substituted derivatives of the triphenylphosphines series (entries 3, 4, 5 and 10 in Table 2) is nicely explainable in terms of the Au- $\mathrm{C}_{1}$ bond strength $\left(\Delta \mathrm{E}_{\text {int }}\right.$ increases from -163.4 to $-183.0 \mathrm{kcal} \mathrm{mol}^{-1}$ for $p$-OMe and $p-\mathrm{CF}_{3}$, respectively), in agreement with the experimental findings. Since we calculated that the weaker the $\mathrm{Au}-\mathrm{C}_{1}$ bond, the lower the protodeauration activation barrier, we expect a direct correlation between the $\Delta \mathrm{E}^{f}$ and the $\Delta \mathrm{E}_{\text {int }}$ values. We should mention here that the $\Delta \mathrm{E}^{\neq}$values are computed at a B2PLYP/COSMO level of theory while the $\Delta \mathrm{E}_{\text {int }}$ values, since we perform the Energy Decomposition Analysis on the LAu-S bond, are computed using BP86 functional without COSMO. In the Supporting Information (Fig. S3) the correlation plot between the $\Delta \mathrm{E}^{\neq}$calculated at both B2PLYP/COSMO and BP86/PCM levels of theory is reported, showing a good correlation, and thus corroborating the reliability of this approach. The correlation plot of $\Delta \mathrm{E}^{\neq} \mathrm{vs} . \Delta \mathrm{E}_{\text {int }}$ in Figure 9 shows that $\Delta \mathrm{E}^{\neq}$is directly proportional to $\Delta \mathrm{E}_{\text {int }}$ with a good correlation coefficient $\left(\mathrm{R}^{2}=0.937\right)$, as we expected from the values in Tables 1 and 2 . We clearly find that the protodeauration rate is mainly dictated by the Au- $\mathrm{C}_{1}$ bond strength.

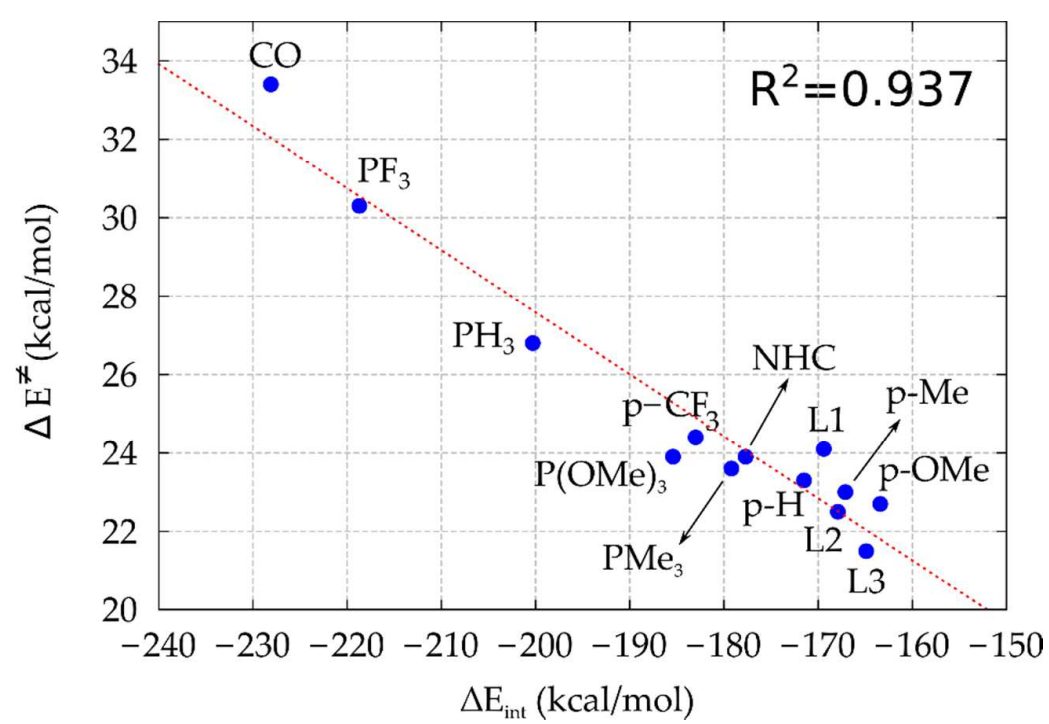

Figure 9. Correlation plot between the protodeauration activation barriers $\Delta \mathrm{E}^{\neq}$(values given in Table 1) and the LAu-S bond interaction energies $\Delta \mathrm{E}_{\text {int }}$ (values given in Table 2). 
A detailed analysis of the different contributions to the Au- $\mathrm{C}_{1}$ interaction energy (Table 2) reveals that variations of $\Delta \mathrm{E}_{\text {int }}$ are mainly due to variations of $\Delta \mathrm{E}_{\text {elst. }}$. We notice that the $\Delta \mathrm{E}_{\text {elst }}$ term is by far the most important contribution to $\Delta \mathrm{E}_{\text {int }}$, going from -307.8 to $-360.2 \mathrm{kcal} \mathrm{mol}^{-1}$ for $p$-OMe and CO, respectively, spanning an energy range of $52 \mathrm{kcal} \mathrm{mol}^{-1}$. On the other hand, $\Delta \mathrm{E}_{\text {Pauli }}$ and $\Delta \mathrm{E}_{\mathrm{oi}} \mathrm{span}$ an energy range of only 15.2 and 14.3 respectively. The plot of $\Delta \mathrm{E}_{\text {int }} \mathrm{vs} . \Delta \mathrm{E}_{\text {elst }}$ is shown in Figure 10. The correlation is very good $\left(\mathrm{R}^{2}=0.998\right)$ and we can thus conclude that the electron donation from the ligand to the $[\mathrm{AuS}]$ fragment weakens the $\mathrm{Au}-\mathrm{C}_{1}$ bond through a lowering of the electrostatic contribution to this bond. The plots of $\Delta \mathrm{E}_{\mathrm{int}} v s$. either $\Delta \mathrm{E}_{\text {Pauli }}$ or $\Delta \mathrm{E}_{\mathrm{oi}}$ show no correlation between these energies, while the plot of $\Delta \mathrm{E}_{\text {int }} v s$. the steric contribution $\Delta \mathrm{E}^{0}\left(=\Delta \mathrm{E}_{\text {elst }}+\Delta \mathrm{E}_{\text {Pauli }}\right)$ shows good correlation as expected, due to the almost constant contribution of the Pauli term (see Fig.s S4 and S5 in the Supporting Information). Finally, the well-known breakdown of the correlation between bond length and bond strength ${ }^{58}$ (in this case activation energy) has been verified by constructing the plots between the protodeauration activation barriers $\Delta \mathrm{E}^{\neq}$and either the L-AuS or the LAu-S bond lengths (see Fig. S6 in the Supporting Information).

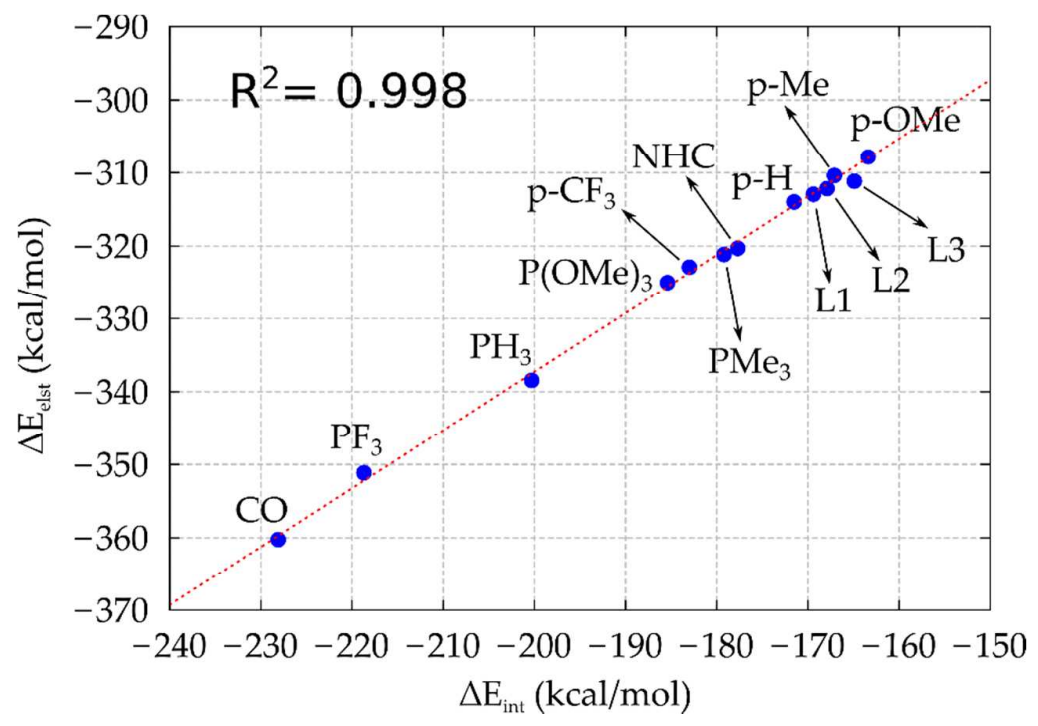

Figure 10. Correlation plot between LAu-S bond interaction energy $\Delta \mathrm{E}_{\text {int }}$ and the electrostatic contribution to it, $\Delta \mathrm{E}_{\text {elst }}$, based on the values given in Table 2 .

\section{Conclusions}

We have carried out a combined DFT/CDF computational study on the ligand effect in the protodeauration step in a gold(I)-catalyzed cyclization reaction for which experimental data were available. Understanding the ligand effect is a challenging task, and indeed it is poorly explored in the literature on a quantitative ground, despite it can yield an in depth control of the outcome and 
the rate of a reaction. A work by Wang et al., ${ }^{23}$ where kinetic studies with different ligands have been conducted, has been used to validate our theoretical approach. We considered a model reaction where a series of thirteen different ligands, spanning a broad range of electronic properties, from electron-donating to electron-withdrawing, have been studied explicitly including the acid molecule for the protodeauration reaction. We carried out a mechanistic analysis and we calculated intermediates and transition states in order to compute activation barriers. We then correlated them with the experimental reaction rates available for the para-substituted triphenylphosphines series, nicely reproducing the experimental Hammett plot.

We analyzed the ligand electron-donating ability through the CD function applied to the L-Au bond. This analysis not only confirmed that the more electron donating ligands lower the protodeauration activation barrier but also allowed us to set the frequently encountered observation in the literature that "more electron-donating ligands speed up the protodeauration reaction" in a quantitative framework, giving a measure of the ligand effect in the activation barriers.

Application of CD function to the L-Au bond where L represents a Buchwald phosphine-like ligand allowed us to study the nature of the interaction between gold and the pendant phenyl ring, which we found to occur through an electrostatic interaction between a negative charge cumulated on $\mathrm{C}_{\mathrm{ipso}}$ and the positive charge on $\mathrm{Au}$ in a direction perpendicular to the $\mathrm{P}-\mathrm{Au}$ bond.

We found that the activation barriers correlate with the LAu-S interaction energies, since they are higher for more strongly interacting LAu and S fragments. This result is consistent with the fact that the LAu-S bond is cleaved during the protodeauration. We analyzed the LAu-S bond energy using the energy decomposition analysis approach, and we found that the changes in the LAu-S strength are mainly due to changes in the electrostatic component of the bond. We conclude that the ligand electron-donation ability lowers the electrostatic component of the LAu-S bond, which in turn lowers the protodeauration activation barriers. This conclusion is particularly important for the Buchwald-type phosphines, in which the additional electrostatic contribution due to the goldpendant phenyl ring interaction nicely explains the good catalytic performances of this class of ligands.

In summary, we gave a theoretical rationale of the ligand effect in the protodeauration step, connecting experimental data and theoretical analysis on a quantitative ground and farther allowing theoretical predictions.

\section{Associated content}

Supporting Information 
Cartesian coordinates of all stationary points, solvent including (PCM) optimized geometries and energies of $\mathrm{LAuS}, \mathrm{RC} 1, \mathrm{RC} 2, \mathrm{TS}_{\text {conc }}$ and $\mathrm{TS}_{\text {step }}$, electron density difference isosurfaces upon formation of the L-[AuS] bond for $\mathbf{L 3}$ ligand, correlation plot between single point BP86/PCM and B2PLYP/COSMO activation barriers, correlation plots between LAu-S bond interaction energy $\Delta \mathrm{E}_{\text {int }}$ and $\Delta \mathrm{E}_{\text {Pauli }}$ and $\Delta_{\mathrm{oi}}$, correlation plot between LAu-S bond $\Delta \mathrm{E}_{\text {int }}$ and $\Delta \mathrm{E}^{0}$, and correlation plots between activation barriers and L-AuS and LAu-S bond lengths. This material is available free of charge via the Internet at http:// pubs.acs.org.

\section{Author information \\ Corresponding Author \\ *E-mail for P.B.: paola.belanzoni@unipg.it \\ Notes}

The authors declare no competing financial interest.

\section{Acknowledgements}

This work was supported by grants from FIRB-futuro in ricerca (RBFR1022UQ, Novel Au(I)-based molecular catalysts: from know-how to know-why (AuCat).

\section{References}

1 (a) Li, Z.; Brouwer, C.; He, C. Chem. Rev. 2008, 108, 3239-3265. (b) Jimenez-Nuñez, E.; Echavarren, A. M. Chem. Rev. 2008, 108, 3326-3350. (c) Gorin, D. J.; Sherry, B. D.; Toste, F. D. Chem. Rev. 2008, 108, 3351-3378. (d) Marion, N.; Nolan, S. P. Chem. Soc. Rev. 2008, 37, 1776-1782.

2 Corma, A.; Leyva-Pérez, A.; Sabater, M.J. Chem. Rev. 2011, 111, 1657-1712.

3 (a) Leyva-Pérez, A.; Corma, A. Angew. Chem. Int. Ed. 2012, 51, 614-635. (b) Rudolph, M.; Hashmi, A.S.K. Chem. Soc. Rev. 2012, 41, 2448-2462.

4 (a) Qian, D; Zhang, J. Chem. Soc. Rev. 2015, 44, 677-698. (b) Dorel, R.; Echavarren, A.M. Chem. Rev. 2015, $115,9028-9072$.

5 Gorin, D. J.; Toste, F. D. Nature 2007, 446, 395-403.

6 Obradors, C.; Echavarren, A.M. Chem. Commun. 2014, 50, 16-28. 
Teles, J.H. In Modern Gold Catalyzed Synthesis, Hashmi, A.S.K.; Toste, F.D., Eds.;Wiley-VCH:Weinheim, 2012; pp 201-236.

$8 \quad$ Wei, Y.; Shi, M. ACS Catal. 2016, 6, 2515-2524.

9 (a) Xi, Y.; Su, Y.; Yu, Z.; Dong, B.; McClain, E.J.; Lan, Y.; Shi, X. Angew. Chem. Int. Ed. 2014, 53, 9817 9821. (b) Seidel, G.; Fürstner, A. Angew. Chem. Int. Ed. 2014, 53, 4807-4811. (c) Yu, Z.; Ma, B.; Chen, M.; Wu, H.-H.; Liu, L.; Zhang, J. J. Am. Chem. Soc. 2014, 136, 6904-6907.

10 Salvi, N.; Belpassi, L.; Tarantelli, F. Chem.- Eur. J. 2010, 16, 7231-7240.

11 Bistoni, G.; Belpassi, L.; Tarantelli, F. Angew. Chem. Int. Ed. 2013, 52, 11599-11602.

12 Zuccaccia, D.; Belpassi, L.; Rocchigiani, L.; Tarantelli, F.; Macchioni, A. Inorg. Chem. 2010, 49, 30803082 .

13 Zuccaccia, D.; Belpassi, L.; Macchioni, A.; Tarantelli, F. Eur. J. Inorg. Chem. 2013, 4121-4135.

14 Zuccaccia, D.; Belpassi, L.; Tarantelli, F.; Macchioni, A. J. Am. Chem. Soc. 2009, 131, 3170-3171.

15 Carreras, J.; Gopakumar, G.; Gu, L.; Gimeno, A.; Linowski, P.; Petukova, J.; Thiel, W.; Alcarazo, M. J. Am. Chem. Soc. 2013, 135, 18815-18823.

16 Ciancaleoni, G.; Belpassi, L.; Tarantelli, F.; Zuccaccia, D.; Macchioni, A. Dalton. Trans. 2013, 42, 41224131.

17 Ciancaleoni, G.; Scafuri, N.; Bistoni, G.; Macchioni, A.; Tarantelli, F.; Zuccaccia, D.; Belpassi, L. Inorg. Chem. 2014, 53, 9907-9916.

18 Döpp,R.; Lothschütz, C.; Wurm, T.; Pernpointner, M.; Keller, S.; Rominger, F.; Hashmi, A.S.K. Organometallics 2011, 30, 5894-5903.

19 Jaimes, M.C.B.; Rominger, F.; Pereira, M.M.; Carrilho, R.M.; Carabineiro, S.A.; Hashmi, A.S.K. Chem. Commun. 2014, 50, 4937-4940.

20 Lavallo, V.; Wright II, J.H.; Tham, F.S.; Quinlivan, S. Angew. Chem. Int. Ed. 2013, 52, 3172-3176.

21 Kronig, S.; Theuergarten, E.; Daniliuc, C.G.; Jones, P.G.; Tamm, M. Angew. Chem. Int. Ed. 2012, 51, 32403244.

22 Wang, Y.; Wang, Z.; Li, Y.; Wu, G.; Cao, Z.; Zhang, L. Nature Comm. 2014, 5, 3470.

23 Wang, W.; Hammond, G. B.; Xu, B. J. Am. Chem. Soc. 2012, 134, 5697-5705.

24 Gaggioli, C. A.; Ciancaleoni, G.; Biasiolo, L.; Bistoni, L.; Zuccaccia, D.; Belpassi, L.; Belanzoni, P.; Tarantelli, F. Chem. Commun. 2015, 51, 5990-5993.

25 Hashmi, A. S. K. Angew. Chem. Int. Ed. 2010, 49, 5232-5241.

26 Liu, L.-P.; Xu, B.; Mashuta, M. S.; Hammond, G. B. J. Am. Chem. Soc. 2008, 130, 17642-17643.

27 Chen, Y.; Wang, D.; Petersen, J. L.; Akhmedov, N. G.; Shi, X. Chem. Commun. 2010, 46, 6147-6149.

28 Zhu, Y.; Yu, B. Angew. Chem. Int. Ed. 2011, 50, 8329-8332.

29 LaLonde, R. L.; Brenzovich Jr, W. E.; Benitez, D.; Tkatchouk, E.; Kelley, K.; Goddard III, W. A.; Toste, F. D. Chem. Sci. 2010, 1, 226-233.

30 BabaAhmadi, R.; Ghanbari, P.; Rajabi, N. A.; Hashmi, A. S. K.; Yates, B. F.; Ariafard, A. Organometallics, 2015, 34, 3186-3195.

31 Jia, M.; Bandini, M. ACS Catal. 2015, 5, 1638-1652 and references therein.

32 Ciancaleoni, G.; Belpassi, L.; Zuccaccia, D.; Tarantelli, F.; Belanzoni, P. ACS Catal. 2015, 5, 803-814. 
Bandini, M.; Bottoni, A.; Chiarucci, M.; Cera, G.; Miscione, G. P. J. Am. Chem. Soc. 2012, 134, 20690-20700. Kim, J. H.; Park, S. W.; Park, S. R.; Lee, S.; Kang, E. J. Chem.-Asian J. 2011, 6, 1982-1986. Zhou, T.; Xu, L.; Xia, Y. Org. Lett. 2013, 15, 6074-6077. Biasiolo, L.; Del Zotto, A.; Zuccaccia, D. Organometallics, 2015, 34, 1759-1765.

37 Frisch, M. J., et al. "Gaussian 09, revision A. 02." Gaussian Inc., Wallingford, CT 270 (2009): 271

(a) Becke, A. D. Phys. Rev. A 1988, 38, 3098. (b) Perdew, J. P. Phys. Rev. B, 1986, 33, 8822. Neese, F. WIREs Comput. Mol. Sci. 2012, 2, 73-78. Grimme, S. J. Chem. Phys. 2006, 124, 034108.

(a) Sinnecker, S., Rajendran, A.; Klamt, A.; Diedenhofen, M.; Neese, F. J. Phys. Chem. A 2006, 110, 22352245. (b) Klamt, A.; Schüürmann, G. J. Chem. Soc., Perkin Trans. 1993, 2, 799-805.

42 Ciancaleoni, G.; Rampino, S.; Zuccaccia, D.; Tarantelli, F.; Belanzoni, P.; Belpassi, L. J. Chem. Theory Comput. 2014, 10, 1021-1034.

$43 \quad$ Mennucci, B. "Polarizable continuum model." WIREs Comput. Mol. Sci. 2.3 (2012): 386-404.

44 Biasiolo, L.; Trinchillo, M.; Belanzoni, P.; Belpassi, L.; Busico, V.; Ciancaleoni, G.; D’ Amora, A.; Macchioni, A.; Tarantelli, F.; Zuccaccia, D. Chem.-Eur. J. 2014, 20, 14594-14598.

45 (a) Baerends, E. J.; Ellis, D. E.; Ros, P. Chem. Phys. 1973, 2, 41-51. (b) Te Velde, G.; Bickelhaupt, F. M.; Baerends, E. J.; Guerra, C. F.; van Gisbergen, S. J. A. J. Comput. Chem 2001, 22, 931-967. (c) ADF2012.01, SCM, Theoretical Chemistry, Vrije Universiteit, Amsterdam, The Netherlands, 2012.

46 (a) van Lenthe, E.; Baerends, E. J.; Snijders, J. G. J. Chem. Phys. 1994, 101, 9783-9792. (b) Van Lenthe, E.; Van Leeuwen, R.; Baerends, E. J. Int. J. Quantum Chem. 1996, 57, 281-293.

47 Belpassi, L.; Infante, I.; Tarantelli, F.; Visscher, L. J. Am. Chem. Soc. 2008, 130, 1048.

48 (a) von Hopffgarten, M.; Frenking, G. WIREs Comput. Mol. Sci. 2012, 2, 43-62. (b) Morokuma, K. J. Chem. Phys. 1971, 55, 1236-1244. (c) Ziegler, T.; Rauk, A. Theor. Chim. Acta 1977, 46, 1-10.

49 Crabtree, R.H. In The organometallic chemistry of the transition metals, 4th ed; Wiley-Interscience: Hoboken, New Jersey, 2005.

50 For one of the first use of the Buchwald-phosphine ligands in gold catalysis see: (a) Nieto-Oberhuber, C.; López, S.; Echavarren, A.M. J. Am. Chem. Soc. 2005, 127, 6178-6179. (b) For a recent review see: Pflästerer, D.; Hashmi, A.S.K. Chem. Soc. Rev. 2016, 45, 1331-1367.

51 (a) Brown, T. J.; Dickens, M. G.; Widenhoefer, R. A. Chem. Commun. 2009, 6451-6453. (b) Pérez-Galán, P.; Delpont, N.; Herrero-Gómez, E.; Maseras, F.; Echavarren, A.M. Chem. Eur. J. 2010, 16, 5324-5332. (c) HerreroGómez, E.; Nieto-Oberhuber, C.; López, S.; Benet-Buchholz, J.; Echavarren, A.M. Angew. Chem. Int. Ed. 2006, 45, 5455-5459.

52 (a) Yin, J.; Rainka, M. P.; Zhang, X.-X.; Buchwald, S. L. J. Am. Chem. Soc. 2002, 124, 1162-1163. (b) RuizCastillo, P.; Blackmond, D. G.; Buchwald, S. L. J. Am. Chem. Soc. 2015, 137, 3085-3092.

53 Billingsley, K. L.; Barder, T. E.; Buchwald, S. L. Angew. Chem. Int. Ed. 2007, 46, 5359-5363.

54 Barder, T. E. J. Am. Chem. Soc. 2006, 128, 898-904.

55 (a) Xu, F.-B.; Li, Q.-S.; Wu, L.-Z.; Leng, X.-B.; Li, Z.-C.; Zeng, X.-S.; Chow, Y.L.; Zhang, Z.-Z. Organometallics 2003, 22, 633-640. (b) Li, Q.-S.; Wan, C.-Q.; Zou, R.-Y.; Xu, F.-B.; Song, H.-B.; Wan, X.-J.; Zhang, Z.-Z. Inorg. Chem. 2006, 45, 1888-1890. 
56 (a) Hirshfeld, F. L. Theor. Chim. Acta 1977, 44, 129-138. (b) Te Velde, G.; Bickelhaupt, F. M.; Baerends, E. J.; Fonseca Guerra, C.; van Gisbergen, S. J. A.; Snijders, J. G.; Ziegler, T. J. Comput. Chem. 2001, 22, 931-967.

57 Ciancaleoni, G.; Santi, C.; Ragni, M.; Braga, A. M. Dalton Trans. 2015, 44, 20168-20175.

58 See, for instance: (a) Kaupp, M.; Metz, B.; Stoll, H. Angew. Chem. Int. Ed. 2000, 39, 4607-4609. (b) Liu, H.-T.; Xiong, X.-G.; Dau, P.D.; Wang, Y.-L.; Huang, D.-L.; Li, J.; Wang, L.-S. . Nat. Commun. 2013, 4:2223, doi: 10.1038/ncomms3223. (c) Frenking, G.; Wichmann, K.; Fröhlich, N.; Grobe, J.; Golla, W.; Le Van, D.; Krebs, B.; Läge, M. Organometallics 2002, 21, 2921-2930. 


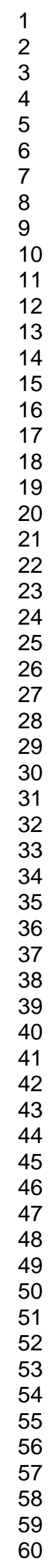




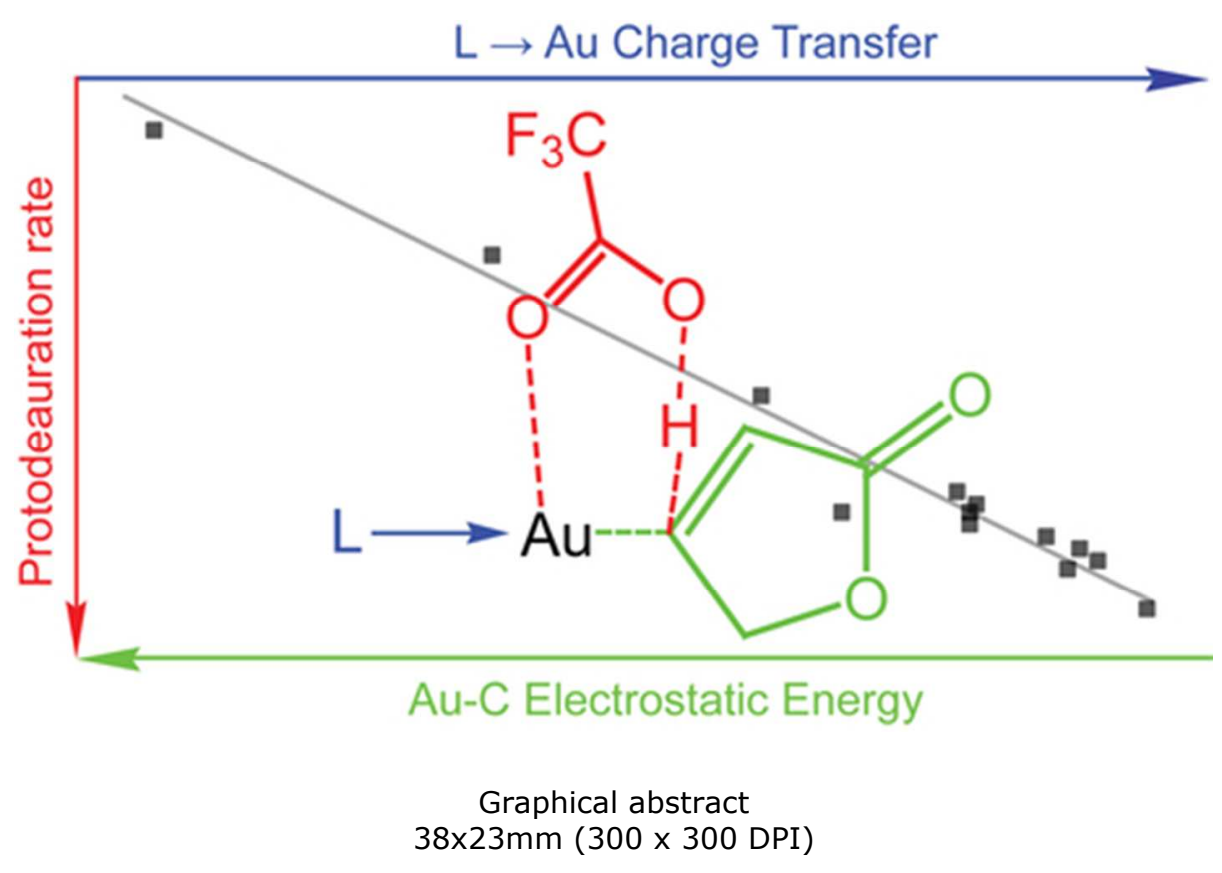

1

2

3

4

5

6

7

8

10

11

12

13

14

15

16

17

18

19

20

21

22

23

24

25

26

27

28

29

30

31

32

33

34

35

36

37

38

39

40

41

42

43

44

45

46

47

48

49

50

51

52

53

54

55

56

57

58

59

60 